\title{
ENTREVISTAS E DEPOIMENTOS: MULTILINGUISMOS E DESAFIOS EM TEMPOS DE PANDEMIA
}

\author{
ENTREVISTAS Y TESTIMONIOS: \\ MULTILINGÜISMO Y DESAFÍOS EN TIEMPOS DE PANDEMIA
}

INTERVIEWS AND TESTIMONIALS:

MULTILINGUALISM AND CHALLENGES IN PANDEMIC TIMES

\begin{abstract}
Fernando Merloto Soave (PR/AM), Altaci Rubim (UNB, Unesco), Rogério Ribeiro (Instituto Cigano do Brasil), Luana Manini (OAB/SP), Vanessa Sagica (Doutoranda em Linguística UFSC), Shirley Vilhalva (UFMS), Algemiro da Silva (Escola Indígena Guarani Karai Kuery Renda)*
\end{abstract}

Depoimentos e entrevistas concedidos a Cristine Gorski Severo

Silvana Aguiar dos Santos**

Este texto tem como objetivo apresentar o posicionamento e a perspectiva de lideranças, agentes públicos e pessoas acadêmicas que estão envolvido/as com as políticas - explícitas ou implícitas (SHOHAMY, 2005) - de promoção, valorização, revitalização e difusão das línguas minoritárias no Brasil, sejam elas línguas faladas por diferentes comunidades indígenas, a diversidade de línguas de sinais e as línguas dos povos ciganos. Atentamos para os desafios e a agentividades desses grupos (SMITH, 1999), mesmo diante das ausências do poder público, de atuar de maneira criativa, solidária e engajada. Julgamos o texto pertinente, especialmente pelo papel que a voz dessas pessoas deve desempenhar na promoção de políticas públicas, uma vez que entendemos que este campo deve acolher os "[...] interesses de uma coletividade, extrapolando os limites de proveitos particularistas ou mesmo individuais, na medida em que deve ser expressão de um debate público, aberto à participação de interesses contraditórios dos interessados diretos ou indiretos" (MELAZZO, 2010, p. 13). As entrevistas e os depoimentos foram feitas entre junho e julho de 2021 e seguiram três perguntas feitas a todas/todos, o que permite uma visão comparada e aprofundada sobre a questão. As respostas foram enviadas por e-mail, na modalidade oral pelo WhatsApp e em vídeo (Libras). Os contatos e entrevistas foram conduzidos por Cristine Severo (UFSC) e Silvana Aguiar dos Santos (UFSC).

\footnotetext{
* Sobre o/as entrevistado/as: trata-se de um grupo heterogêneo de lideranças, agentes públicos e representantes de comunidades que atuam, direta ou indiretamente, em prol das línguas minoritárias/minorizadas: Fernando Merloto Soave (PR/AM), Altaci Rubim (UNB, Unesco), Rogério Ribeiro (Instituto Cigano do Brasil), Luana Manini (OAB/SP), Vanessa Sagica (Doutoranda em Linguística UFSC), Shirley Vilhalva (UFMS), Algemiro da Silva (Escola Indígena Guarani Karai Kuery Renda). E-mails: fernandosoave@mpf.mp.br; altacirubim2017@gmail.com; rogerioribeirosciganocalon@gmail.com; maniniluana@gmail.com; vanessa.sagica@yahoo.com.br; shirley.vilhalva@ufms.br;

\footnotetext{
** Sobre as entrevistadoras: Cristine Severo (UFSC) e Silvana Aguiar dos Santos (UFSC) editam este número especial. Cristine Severo é docente do Programa de Pós-Graduação em Linguística (PPGL/UFSC) e coordenadora do grupo Políticas Linguísticas Críticas e Direitos Linguísticos. Silvana Aguiar dos Santos é docente do Programa de Pós-Graduação em Estudos da Tradução (PGET/UFSC) e coordenadora do Programa de Extensão TILsJuR - Tradutores e intérpretes de línguas de sinais na área. E-mails: crisgorski@gmail.com; s.santos@ufsc.br.
} 
Seguem as perguntas feitas:

I Fale sobre você e sua atuação junto aos grupos minorizados/minoritários.

II Quais os desafios enfrentados envolvendo as línguas (e acesso à informação) no contexto da pandemia?

III Se fosse possível sugerir ações em torno das línguas e da comunicação voltadas para essas comunidades, qual ou quais seriam?

As pessoas convidadas para responder a essas questões são agentes públicos, representantes importantes, lideranças ou desempenham papel relevante em relação às comunidades linguísticas minoritárias, tanto internamente à comunidade, como na sua relação com a esfera pública. Apresentamos, abaixo, os nomes que integraram os depoimentos e as entrevistas:

1) Fernando Merloto Soave, Procurador da República/Ministério Público Federal (PR/AM).

2) Altaci Rubim, docente da UNB, representante da América Latina e Caribe da UNESCO no GT Mundial da Década das Línguas Indígenas e pertencente ao povo Kokama.

3) Rogério Ribeiro, cigano da etnia Calon, presidente do Instituto Cigano do Brasil-ICB e membro consultivo da comissão da Igualdade Racial da $\mathrm{OAB} / \mathrm{CE}$.

4) Luana Manini, advogada, membro efetiva da Comissão dos Direitos das Pessoas com Deficiência da OAB/SP e tradutora e intérprete no par linguístico Libras-Português.

5) Vanessa Sagica, pertencente ao povo Macuxi e doutoranda em Linguística na Universidade Federal de Santa Catarina (UFSC).

6) Shirley Vilhalva, docente da Universidade Federal de Mato Grosso do Sul (UFMS), liderança e escritora surda, atuante na comunidade surda e pesquisadora das línguas de sinais indígenas. Acesso ao vídeo em Libras: https://drive.google.com/file/d/11nTyX4RrxAI2JNH9xYwfuJUoocaHa yD/view ${ }^{2}$

7) Algemiro da Silva (Karai Mirim), formado em sociologia, mestrando em Linguística. Atua na Escola Indígena Guarani Karai Kuery Renda na Aldeia Sapukai.

A seguir, optamos por agrupar as respostas conforme as perguntas, seguindo a sequênciua dos nomes apresentados anteriormente.

\section{FALE SOBRE VOCÊ E SUA ATUAÇ̃̃O JUNTO AOS GRUPOS MINORIZADOS/MINORITÁRIOS ${ }^{3}$}

\section{1) Fernando Merloto Soave (PR/AM)}

Procurador no Amazonas desde 2014, atuando na 6a CCR (direitos indígenas e demais povos tradicionais). Busca priorizar atuações com resultados práticos, em geral as que são realizadas em formato de rede têm maior potencial de ter resolutividade. Um exemplo interessante de atuação nossa neste sentido é: http://www.mpf.mp.br/atuacao-tematica/ccr6/catrapovosbrasil

\section{2) Altaci Rubim (UNB)}

Doutora em Linguística pela Universidade de Brasília e mestra em Sociedade e Cultura na Amazônia pela Universidade Federal do Amazonas. Foi selecionada em 2020 pela UNESCO para representar o Brasil no GT Mundial da Década Internacional das Línguas Indígenas (2022-2032).

\section{3) Rogério Ribeiro (Instituto Cigano do Brasil)}

presidente do Instituto Cigano do Brasil-ICB. Pertencente à etnia Calon e membro consultivo da comissão da Igualdade Racial da $\mathrm{OAB} / \mathrm{CE}$. O Instituto de Cultura, Desenvolvimento Social e Território do Povo Cigano do Brasil, Instituto Cigano do Brasil-ICB, desde de a sua implementação no ano de 2018, vem desenvolvendo ações para a promoção e defesa dos direitos dos povos ciganos no Brasil. O ICB é uma organização de abrangência nacional e internacional que oferece serviços gratuitos e permanentes para pessoas ciganas, especialmente aquelas de baixa renda ou beneficiárias de programas governamentais, não fazendo nenhuma

\footnotetext{
${ }^{2}$ Nota do Editor: mantivemos os links no corpo do texto justamente para facilitar o acesso, em detrimento da obediência às normas da ABNT.

${ }^{3}$ Para uma discussão sobre o conceito de língua minoritária e as relações de poder que minorizam grupos e línguas, produzindo línguas minorizadas, ver Ponso (2017).
} 
distinção de gênero, sexualidade, cor, etnia, origem, classe social, crença política ou religiosa. Podem compor os quadros do ICB ciganos, descendentes, transcendentes, simpatizantes da cultura cigana, a partir de 18 anos. O ICB é uma organização de abrangência nacional com estrutura organizacional que contabiliza 16 coordenações estaduais e ou municipais nos estados do Maranhão, Piauí, Ceará, Rio Grande do Norte, Paraíba, Alagoas, Sergipe, Bahia, Distrito Federal, Mina Gerais, Espirito Santo, Rio de Janeiro, São Paulo, Rio Grande do Sul, Santa Catarina e Pará, duas (02) coordenações internacionais nos países de Portugal e Bélgica e GTs temáticos, compostos por convidados, ciganos e não ciganos de todos os estados brasileiros (técnicos e acadêmicos).

\section{4) Luana Manini $(\mathrm{OAB} / \mathrm{SP})$}

Advogada e tradutora e intérprete no par linguístico Libras-Português: Iniciou há 15 anos o seu aprendizado na Língua Brasileira de Sinais - LIBRAS em um espaço religioso. Com o seu desenvolvimento linguístico e a convivência com as diferentes comunidades surdas, experenciou as dificuldades e violações que sofriam e passou a esclarecer seus direitos e deveres. Por se compreender bilíngue e ter interesse em atuar com as questões de tradução e interpretação, cursou uma pós graduação, que a permitiu adquirir competência linguística, extralinguística e emocional, fortalecendo o seu trabalho com os clientes surdos e a consultoria de tradução dos materiais e das provas na esfera jurídica. Atualmente, coordena o projeto Manini Jurídico, com a finalidade de contribuir com o letramento jurídico e encurtar o distanciamento dos surdos sinalizantes no acesso às informações legais, para exercerem sua cidadania em igualdade de condições com os falantes do português. Na Comissão da OAB/SP, coordena o GT de Pessoas com Deficiência Sensorial, cujo objetivo é estudar e propor medidas voltadas para o bem estar das pessoas com deficiência, além de zelar pelo aprimoramento e cumprimento das normas pertinentes a este grupo.

\section{5) Vanessa Sagica (Doutoranda/UFSC)}

Realiza pesquisa de doutorado em prol da valorização e do resgate identitário do povo Macuxi e Wapichana, do qual também faz parte. Justifica-se essa atuação porque com a demasiada inserção na sociedade hegemônica esses povos têm cada vez mais silenciado essas práticas em detrimento das do Estado, ocasionando um apagamento linguístico e identitário. Ainda que o Estado de Roraima abrigue a maioria dos Macuxi e Wapichana, que também se encontram nas regiões da Guiana Inglesa e Venezuela, e tenha cooficializado essas línguas em uma determinada área do Estado, faz-se necessário buscar políticas públicas que insiram essas línguas num contexto ainda maior da sociedade.

\section{6) Shirley Vilhalva (UFMS)}

Atuante na comunidade surda e pesquisadora das línguas de sinais indígenas. Foi professora e diretora de Escola Estadual de Surdos/CEADA e professora no CAS/MS. Dedicou 25 anos como voluntária na FENEIS, 15 anos como voluntária na ASSUMS, contribuiu como Conselheira do CONSEP e do CONADE. Atua na educação de surdos em Mato Grosso do Sul há 36 anos, trabalhando com surdos urbanos e indígenas surdos.

Acesso ao depoimento em Libras: https://drive.google.com/file/d/11nTyX4RrxAI2JNH9xYwfuJUoocaHa yD/view

\section{7) Algemiro da Silva (Karai Mirim, Escola Indígena Guarani Karai Kuery Renda)}

Atua como professor do colégio guarani Karai Kuery Renda, no $2^{\circ}$ segmento. Auxilia a comunidade, o cacique e a associação indígena dentro da comunidade. Na seção jurídica, auxilia a comunidade para encaminhar ou adquirir documentos, como CPF. Vive há 30 anos na comunidade, onde residem 120 famílias. Atua com os projetos Ponto de Cultura e Semente Guarani, que são frutos de editais do governo. 


\section{QUAIS OS DESAFIOS ENFRENTADOS ENVOLVENDO AS LÍNGUAS (E ACESSO À INFORMAÇÃO) NO CONTEXTO DA PANDEMIA?}

\section{1) Fernando Merloto Soave (PR/AM)}

Há diversos desafios. Por ex, a ausência de acesso à informação adequada não permite o exercício dos direitos regularmente e nem a adequação das políticas ao contexto cultural de cada povo. Isto acontece no acesso às políticas públicas, como bolsa família e outros benefícios; no acesso às políticas de compras públicas (que podem possibilitar geração de renda e maior autonomia), e por aí vai. A questão das línguas em si evoca o tema das tradições. A ruptura das tradições (língua inclusa) provoca danos sociais imensos, inclusive maior alcoolização e drogadição, entre outras causas. O fortalecimento das tradições (língua inclusa) tende a trazer maior empoderamento e força para o combate aos ilícitos, às pressões e cooptações externas, etc.

\section{2) Altaci Rubim (UNB)}

Nosso desafio foi transformar as nossas oficinas presenciais em cursos remotos de ensino de língua e acompanhar as aulas do Centro de Línguas Kokama na modalide remota, além das atividades na própria UNB, por meio do ensino remoto. O primeiro passo foi lidar com a formação de professores que ocorria através de duas oficinas presenciais (em julho e janeiro, no período de férias). Na pandemia, elas passaram a ocorrer através da mídia social, pelo WhatsApp. Eu e meus alunos - Mariana, Luis Felipe e Maria Madalena - criamos um projeto para que as atividades do grupo de curso básico da língua kokama fossem enviadas em forma de post (do canva), para que não ficassem pesadas e fossem acessadas com internet baixa. Os professores preferiram que as atividades fossem em formato pdf para que pudessem imprimir e usá-las nas escolas. $\mathrm{O} 2^{\circ}$ módulo priorizou o uso do material em pdf. O desafio foi o acesso à internet. Os professores neste contexto são esforçados: saem das aldeias, colocam crédito no celular, abaixam as atividades, as imprimem e compartilham. Muitos terminaram o curso, mas também tivemos desistência. Sabemos que a desistência na modalidade remota tem sido alta em qualquer esfera.

Outro exemplo de atuação foi acompanhar os centros de língua kokama. O lado positivo nesses centros foi o deslocamento do ensino, que saiu das quatro paredes dos centros e retornou para o seio da família. As crianças recebem as atividades pelo WhatsApp e as realizam juntamente com pais e avós, reforçando a língua e cultura. Avançamos nesta proposta.

Registro, ainda, o depoimento da profa Laura, do centro de ciências e saberes Kokama Lua Verde Yatsi Ikira (Manaus) sobre a experiência de ensino remoto. Segundo ela: "inciamos nossas atividades na modalidade remota e tem sido um grande desafio. Estamos aprendendo sobre as tecnologias e novos métodos de ensino. Na Lua Verde ensinamos as crianças e estamos utilizando jogos, aplicativos, cruzadinhas, jogo dos sete erros, de forma que elas possam aprender de maneira dinâmica e didática. Utilizamos figurinhas e emojis no whats up e as crianças têm se identificado com a metodologia, com resultados positivos. Procuramos trabalhar com aquilo que é disponível às crianças. Nem todos têm acesso à internet. Pensando nisso, encurtamos o envio de imagens. Enviados duas por dia, bem elaboradas, e a experiência tem sido prazerosa. Recebemos feedback dos pais dizendo que as crianças gostam. Elas, também, estão interagindo com os pais na língua kokama, pedindo bênção nesta língua.”

\section{3) Rogério Ribeiro (Instituto Cigano)}

A falta de assistência por parte do Poder Público, a ansiedade e a angústia têm sido sintomas comuns nessa fase que os Povos Ciganos vêm vivendo. As incertezas de lidar com uma doença desconhecida e que ainda não tem vacina preventiva deixam os Ciganos com medo. Todo sofrimento e toda morte humana, independentemente da raça, cor e cidadania, deveria sensibilizar as pessoas, principalmente, aquelas que tem condições de ajudar.

Com a chegada do Coronavírus, a ajuda humanitária e as parcerias se tornaram extremamente importantes. O ICB confeccionou máscaras personalizadas, criou a campanha fique na Barraca Ciganos, elaborou uma cartilha com as principais orientações sobre a Covid- 19, criou o Mapa de Óbitos pela Covid-19 dos Povos Ciganos, além de uma página no facebook sobre o memorial das vítimas de Covid-19 dos Povos Ciganos. Sobre as parcerias, diante da ausência de políticas públicas específicas para os Povos Ciganos, O ICB conseguiu ótimas parcerias, como: Mesa Brasil Sesc Ceará que, desde abril de 2020, vem recebendo doações e compartilhando com as famílias ciganas cearenses; a Natuagua forneceu álcool 70; o governo do estado forneceu algumas 
máscaras; o Instituto INEC forneceu cestas básicas para algumas famílias. Além disso, foi realizado cadastro na rede de cultura dos artistas e trabalhadores da cultura através do mapa cultural.

\section{4) Luana Manini $(\mathrm{OAB} / \mathrm{SP})$}

Com a pandemia, todas as pessoas precisaram rever seus conceitos, adaptar os negócios e atualizar obrigatoriamente suas habilidades tecnológicas. No Poder Judiciário não foi diferente. Nós, operadores do direito (Magistrados, Ministério Público e Advogados), fomos forçados a mudar e passamos a realizar as audiências e atendimento ao cliente preso de forma virtual. Apesar dos benefícios prometidos na realização das audiências remotamente, como à facilidade de acesso, agilidade no andamento processual e redução dos gastos, para a Comunidade Surda, a mudança apontou outros e novos desafios. A LIBRAS é uma língua de modalidade gestual-visual, diferente da língua portuguesa, de modalidade oral-auditiva, e essa diferença demonstra que algumas questões de acessibilidade, que parecem atender um determinado grupo, não contemplam ou dificultam a participação dos surdos sinalizantes em razão das peculiaridades da língua. O primeiro desafio que enfrentei foi e permanece em relação às diferentes plataformas e recursos de acessibilidade usados no acesso aos serviços do Tribunal. Cada sistema tem funcionamento e funcionalidades diferentes, impossibilitando, por exemplo, a fixação do intérprete na tela e o acompanhamento satisfatório da parte surda (autor, réu, testemunha ou terceiro interessado) devido à movimentação e alteração constante do layout a cada manifestação em voz dos ouvintes na sala, além da ausência de legenda simultânea em português. Ademais, as expressões faciais e corporais que pertencem à gramática da língua e dão sentido na comunicação ficam prejudicadas no pequeno espaço (janela) das salas virtuais. Somado a isso, a maioria dos surdos utiliza o aparelho celular para acompanhar a audiência virtual e a falta de equipamento adequado, como computador ou tablet que tem uma tela mais ampla, é um desafio.

$\mathrm{O}$ acesso à Internet, a falta de qualidade na conectividade e o uso das máscaras no Sistema Prisional prejudicaram o nosso trabalho como profissional intérprete de Libras, devido à imprecisão das escolhas tradutórias em decorrência da baixa visualidade. Tal fato torna as partes surdas e as pessoas que não têm esses recursos ou acesso a esses serviços de qualidade ainda mais vulneráveis. Nesse caso, o advogado pode solicitar o cancelamento das audiências virtuais ou requerer que se tornem híbridas, justificando as razões. Todavia, o prazo para a realização de audiências presenciais ainda está com data a definir (sabe-se lá quando) ou é prorrogada pelo juiz, para um período muito distante, tornando o acesso à justiça para o surdo injusto, além de moroso. Infelizmente, as sugestões para sanar esses problemas, na ótica dos falantes de línguas orais são: atendimento via chat, ligações, mensagem de texto ou áudios, o que definitivamente não atende o direito linguístico do surdo. A tecnologia nos oferece diferentes caminhos e auxilia em muitas questões, no entanto, para os surdos sinalizantes, a participação humana e presencial é ainda a melhor forma de acesso e comunicação.

\section{5) Vanessa Sagica (Doutoranda/UFSC)}

Especificamente, na região do Bonfim, em Roraima, está localizada a Comunidade Indígena Manoá, que abriga uma parte do meu povo Macuxi. Nessa comunidade, a língua macuxi não tem mais sido colocada tanto em cena, os seus falantes se tronaram raros, as reuniões com o Tuxaua e as demais ações são todas realizadas na língua oficial do país. Isso se torna preocupante, uma vez que se trata de ações que competem apenas aos integrantes da comunidade, ainda que as demandas sejam levadas às instâncias burocráticas na língua oficial. Acredito que, no seio da comunidade, deveria ser incentivada a prática ou mesmo a inserção daquilo que envolve a língua originária. Esse excesso do uso da língua dominante exclui uma parcela que ainda se comunica em sua língua materna e/ou dos que não dominam a língua oficial.

Na pandemia, por exemplo, os indígenas compreendiam que estava se passando algo grave, mas a intensidade daquilo que era provocado pelo vírus se tornou mais significativa e real quando os indígenas tiveram acesso a vídeos e, posteriormente, a panfletos que explicavam os sintomas e as ações preventivas na língua macuxi e wapichana. O panfleto surtia efeito, primeiramente, nos falantes das línguas que tinham o conhecimento da escrita, sendo que estes puderam (re)transmitir informações aos que dominavam apenas a oralidade. Assim, alguns sintomas do Corona Vírus puderam ser contextualizados às doenças que são alarmantes e perigosas de serem contraídas no entendimento desses povo, como por exemplo: "tosse seca" foi traduzida como "He he" na língua macuxi e, é entendida como uma tosse insistente que não passa, a exemplo da tuberculose. 
6) Shirley Vilhalva (UFMS), atuante na comunidade surda e pesquisadora das línguas de sinais indígenas. Acesso em Línguas de Sinais: https://drive.google.com/file/d/11nTyX4RrxAI2JNH9xYwfuJUoocaHa yD/view

\section{7) Algemiro da Silva (Karai Mirim)}

Com a pandemia, nossa vida e cotidiano ficaram atípicos. A comunidade está em recuperação, voltando a fazer trabalhos e artesanatos, mas ainda não como antes. Mantemos nossa língua, cantos e danças. O colégio também parou totalmente. Além de mim, há mais seis professores guarani e todos ficamos com nossos contratos. Na nossa aldeia, praticamente $50 \%$ foram infectados. Somos 480 pessoas, das quais 240 foram infectadas. Atuo na aldeia como um dos representantes e coordenador da campanha que fizemos - como sociedade civil - junto a professores e colaboradores da cidade do Rio de Janeiro.

\section{SE FOSSE POSSÍVEL SUGERIR AÇÕES EM TORNO DAS LÍNGUAS E DA COMUNICAÇÃO VOLTADAS PARA ESSAS COMUNIDADES, QUAL OU QUAIS SERIAM?}

\section{1) Fernando Merloto Soave (PR/AM)}

a) maior incentivo e articulação junto às universidades públicas (e privadas) para apoio no resgate linguístico aos povos com interesse.

b) criação de cartilhas, vídeos de whatsapp e materiais de políticas públicas e também lúdicos na língua de cada povo, pelos entes públicos responsáveis nas diferentes políticas com apoio da FUNAI, da academia, do próprio povo interessado.

c) instalação de pontos de internet nas comunidades interessadas (isto facilitaria muito o acesso à informação, o contato imediato diante de violações, etc).

d) fomento à criação de redes de comunicação locais onde inexistentes (seja via rádio, impresso, whatsapp etc.).

\section{2) Altaci Rubim (UNB)}

O desafio é a internet, pois nem todos têm acesso. Quando possível, colaboramos, mas, no geral, são os pais que providenciam alimentação e, também, o acesso à internet. Na UNB, estamos realizando atividades pelo modelo remoto, usando o google meet, podcast, e outros intrumentos. Observamos que é muito cansativo para os estudantes. No meu caso, não observo desistência, mas sei que é cansativo para os alunos, ainda mais diante de perdas e sofrimentos psicológicos.

\section{3) Rogério Ribeiro (Instituto Cigano do Brasil)}

Produção de cartilhas específicas, além da implantação do quesito etnia nos formulários/cadastros do Sistema de Saúde. Importante incentivar a veiculação de toda a produção oficial de informação nos meios de comunicação tradicionais e em rede sociais, ou através de cartilha, folders, panfletos etc. Sobre o coronavírus, pensando na acessibilidade para a pessoa com deficiência, importante observar os recursos de linguagem em braile, libras, audiodescrição e legenda; produzir material informativo/educativo e vídeo institucional sobre os serviços, programas, projetos, controle social e canais de participação social, além de realizar ampla divulgação na comunidade cigana, haja visto a pouca alfabetização de muitos adultos.

\section{4) Luana Manini (OAB/SP)}

A Libras já é reconhecida pela Lei $n^{a}$ 10.436/02 como meio legal de comunicação e expressão oriundas das comunidades surdas. No entanto, é preciso apoiar o seu uso e difusão para que diferentes profissionais conheçam e possam se empenhar na comunicação com os surdos. Na pandemia os desafios são agravados pelo afastamento social e a tecnologia tem sido uma aliada. Não na substituição do profissional por avatar, mas como impulsionamento para o conhecimento da língua e desafios que as Comunidades Surdas enfrentam cotidianamente. Para tanto penso que é possível:

- Ampliar o conhecimento sobre as comunidades surdas no sistema Judiciário, Policial e Penitenciário.

- Capacitar os operadores de direito na área jurídica para que os surdos acessem esses serviços com segurança e autonomia.

- Identificar as ações, os materiais e providenciar os recursos de acessibilidade (janela de Libras, audiodescrição e LSE) em todos os informes de serviços públicos.

- Fortalecer as Centrais de Intérpretes de Libras e formações destes profissionais. 
- Potencializar sistemas de atendimento (SAC, canais) que possibilite o envio de vídeo em LIBRAS com profissionais capacitados para dar o devido suporte.

\section{5) Vanessa Sagica pertence ao povo Macuxi; doutoranda em Linguística na Universidade Federal de Santa Catarina (UFSC)}

As nuances linguísticas somente são percebidas por meio de políticas linguísticas que assegurem às línguas minoritárias, ações contextualizadas às suas comunidades. Em se tratando de um contexto pandêmico, essas políticas se tornam ainda mais urgentes, para que os indígenas sejam de fato inseridos aos eventos da sociedade hegemônica - tendo atenção às suas especificidades sociolinguísticas - bem como a garantia da sobrevivência de seus povos originários.

6) Shirley Vilhalva (UFMS), atuante na comunidade surda e pesquisadora das línguas de sinais indígenas. Acesso em Línguas de Sinais: https://drive.google.com/file/d/11nTyX4RrxAI2JNH9xYwfuJUoocaHa yD/view

\section{7) Algemiro da Silva (Karai Mirim)}

Produção de cartilhas e materiais de divulgação nas línguas indígenas, promoção e acesso às políticas públicas em prol das populações indígenas.

\section{REFERÊNCIAS}

MELAZZO, E. Ss. Problematizando o conceito de políticas públicas: Desafios à análise e à prática do planejamento e da gestão. TÓPOS, v. 4, n. 2, p. 9-32, 2010.

PONSO, L. C. Situação minoritária, população minorizada, língua menor: uma reflexão sobre a valoração do estatuto das línguas na situação de contato linguístico. Revista Gragoatá(UFF), v. 22, p. 184-207, 2017.

SHOHAMY, E. Language Policy Hidden Agendas and New Approaches. Londres: Routledge, 2005.

SMITH, L. T. I. Decolonizing Methodologies Research and Indigenous Peoples. London: Zed Books Ltd/University of Otago Press, 1999.

\section{$(\circledast) \circledast \ominus$}

